\title{
Digital Transformation as a Strategy of Value Creation in Industry
}

\author{
Kristina Lachova ${ }^{1, *}$ \\ Technical University of Kosice, Faculty of Mechanical Engineering, Institute of Management, Industrial and Digital Engineering, Park Komenskeho \\ 9, 04200 Kosice
}

\begin{abstract}
The strategies of many organizations have recently included digital transformation. Digital initiatives in enterprises have proven to be essential tools for ensuring the sustainability of business processes. Trends from previous periods remain relevant, but the priorities for their deployment are changing and speed of implementation of advanced digital technologies is accelerating. This article focusses on digital transformation as a key future strategy along with value creation.
\end{abstract}

Keywords: digital transformation; digitization; strategy; value creation; industry

\section{Introduction}

Digital transformation of industry is unstoppable and it's riding on the wave of new innovations. Digitization moves the world. In recent years, many professions have emerged that were not 10 years ago. This trend will continue, and industry must be prepared for it more than ever before. Digital technology development plans are essential part of business strategies. The path of economic and operational excellence of industrial enterprises leads through numerous in-house digitization projects. Gradual deployment of advanced digital technologies in processes on production lines is one of the main priorities. Digital transformation became a necessary strategy for each company in the industry [8]. It is creating new profit by transforming customer expectations and how companies can address them. Digital transformation is the integration of digital technology into all areas of a business, fundamentally changing how companies operate and deliver value to customers. It is also a cultural change that requires organizations to continually challenge the status quo, experiment, and get comfortable with failure $[8,9]$. Digitization requires massive investment and the attention is focused on the ratio between the costs incurred for digitization and at the same time to the values that digitization brings. Analysis of how digital transformation contributes to value creation is therefore necessary [4].

\section{Digital Transformation as a Strategy}

As more and more businesses are now engaging in digitization, it is essential to have a well-planned digital transformation strategy. Businesses that are not agile enough to develop innovative business models and a comprehensive strategy are lagging the competition. From manufacturers who sell products linked to value-added services, to resellers who provide a seamless customer experience through multichannel communication, companies must strive to provide an excellent experience for every customer.

To guarantee the successful implementation of a digital transformation strategy and take advantage of its effects on the organization, it is necessary to align use of 


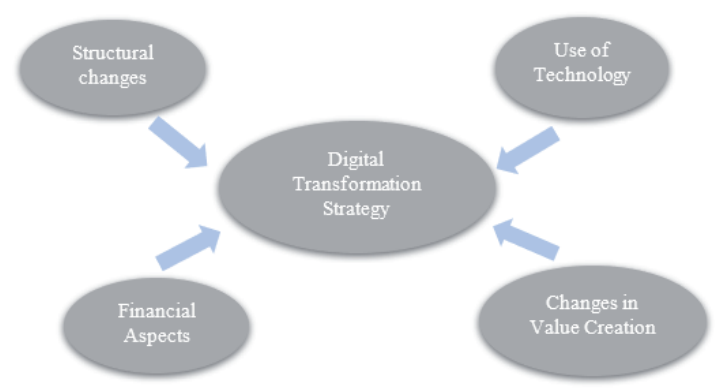

Figure 1: Key elements to be align for successful digital transformation [7]

technologies, structural changes, changes in value creation and financial aspects of digital transformation.

\subsection{Digital Transformation Technologies}

Digital transformation uses mostly technologies to create value for stakeholders, innovate and acquire the capabilities to rapidly adapt to changing circumstances. Enterprises in industry are moving towards so called smart factories which are characterized by the Digital Twin, CPS Cybernetic Physical Systems, Internet of Things, Internet of Services, Big Data, Cloud Computing, Product Lifecycle Management Systems and Digital Manufacturing.

Digital Twin is an interactive tool for effective team planning of production and logistics systems. It allows to easily design a logistics or production concept using 3D models and through virtual reality choose the best variant. The creation of the digital twin consists of a 3D scan of all objects in the production hall. For this purpose, usually a 3D laser scanner is used. After scanning all objects, the individual scans are combined into a complete cloud. From the cloud, 3D models of workplaces and objects are gradually created. 3D models are then inserted into the software for the final creation of a 3D form of production.

Digital twin technology allows [7]:

- Designing the production and logistics process in virtual reality,

- 3D layout planning with the task to create digital models for 3D layout planning with all active production and logistics processes,

- Allows plant teams to simulate various scenarios,

- Create working models for all processes to allow local static simulations to be run with key variable changes to confirm capital requirements.

Digital twin represents an original and innovative approach to planning and designing production and logistics systems. The 3D clone of the production

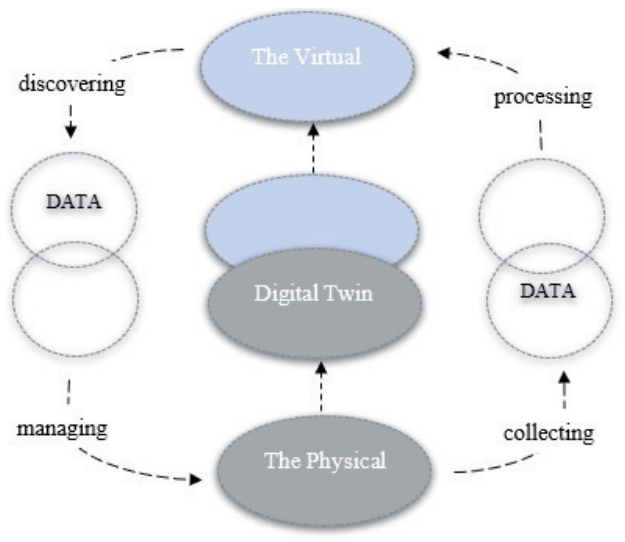

Figure 2: Digital twin schematic principle [8]

hall during the workshops allows to change the production layout with a simple movement of the hand on the screen and thanks to the interactivity immediately see the effects of changes, as the system realistically redraws material flows and recalculates monitored indicators. Digital twin allows easy handling and positioning objects in the scene, as well as virtual tour through virtual reality headset. It answers the question "What happens if ...?". Through simulations, it is possible to create different numbers of experiments, compare them and implement only the best one. This saves time and possible costs that could be incurred by making the wrong decision. Objects created in digital twin are automatically connected to the logistics network and a logistics system can be redesigned. First step is creating material flows which consist of creating transport connections between sources of sender-receiver, parameterization of material flow product/part, the quantity transported, type handling equipment etc. Once material flow is created, optimization and evaluation can begin. The biggest benefit is that system automatically searches for the proposed direction of the material flow along the shortest path within the logistics chain. Another benefit is that system immediately evaluates the parameters of material flow like the length of material flow, time spent of handling equipment for material flow and rate of material flow.

Many experiments can be created due to digital twin, even without a direct connection with the physical production line. Is possible to answer questions like what will happen in the overall production line when a certain parameter is 


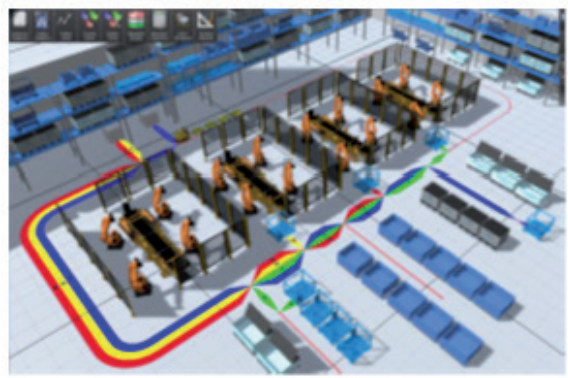

Figure 4 Material Flow redesign in digital twin

changed. In other words, the model allows one to modify production parameters, then to monitor the behaviour of the system without the risk of financial loss in the real production line. If we connect the simulation model to the real system, this opens another possibility to optimize the production system.

Another key focus area is the "Internet of Things" and the necessity to build a way to central monitoring, management and coordination of large amounts of diverse data. This can be achieved mainly by increasing the level of software capability while ensuring the use of communication standards and adequate level of security. Strong emphasis needs to be placed on building digital trust. The aim should be to ensure the security and credibility of information in an environment of mutual cooperation in the form of comprehensive risk management.

PLM software solutions process all product data throughout its life cycle, from initial virtual designs, through prototypes, product manufacturing, sales, to the appropriate end-of-life disposal and recycling process. The system also covers the comprehensive management of product data between all entities, including customers, suppliers and all other resources needed to implement the product. PLM is compiled for each company as an original solution that considers specific conditions and needs. Creating a suitable PLM solution requires a holistic approach based on analysis of all activities that must be performed at all levels of the life cycle of the implemented product.

Corporate culture and people are the driving forces of digital transformation. Employees must understand the changes that are happening in the company and should know how they can be part of such changes. Behind the success of any company, which is easiest to express in terms of

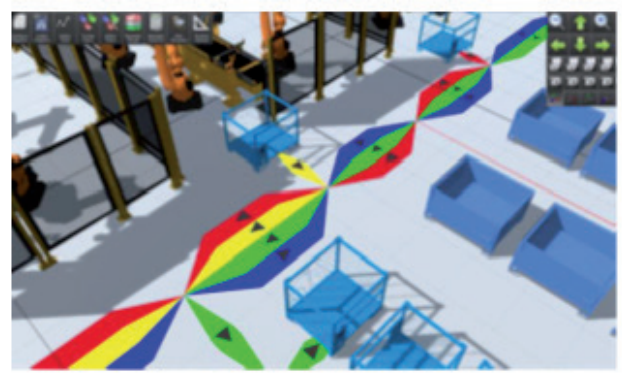

achieved economic results, it is necessary to see the competencies of the people who work for it. Old hierarchical systems should replace by agile systems and modern innovative practices. Technological changes have three important effects [8]:

- they eliminate jobs by replacing human work with robot work,

- changing the qualification requirements for workers in many professions,

- create new professions.

Most requested skills of employees are critical and analytical thinking, as well as problem solving Better computer knowledge is required from job applicant. Within digital transformation, the most needed positions include a data analyst, a robotics specialist, an engineer, a software and application developer, and a social networking specialist. Digital transformation represents an evolution and a great opportunity for personal and professional workforce shift.

\section{Value creation by digitization}

Digital services based on data analysis and comprehensive digital solutions for the entire ecosystem are the main source of significant revenue growth. To be able to create real value digitization must not only involve continuous monitoring of current products and processes but it must go beyond this framework. The followed tools must take a place [2]:

- Real-time quality management based on data analyst,

- Introduction of new flexible and customer-oriented concepts into production,

- Real-time production information, optimization based on data analytics,

- Predictive maintenance of key equipment, optimization of repair and maintenance plans brings increased operating time,

- Vertical integration from sensors via MES to real-time production planning to increase OEE and production throughput,

- Horizontal integration, track-and-trace technology for logistics optimization and inventory management 


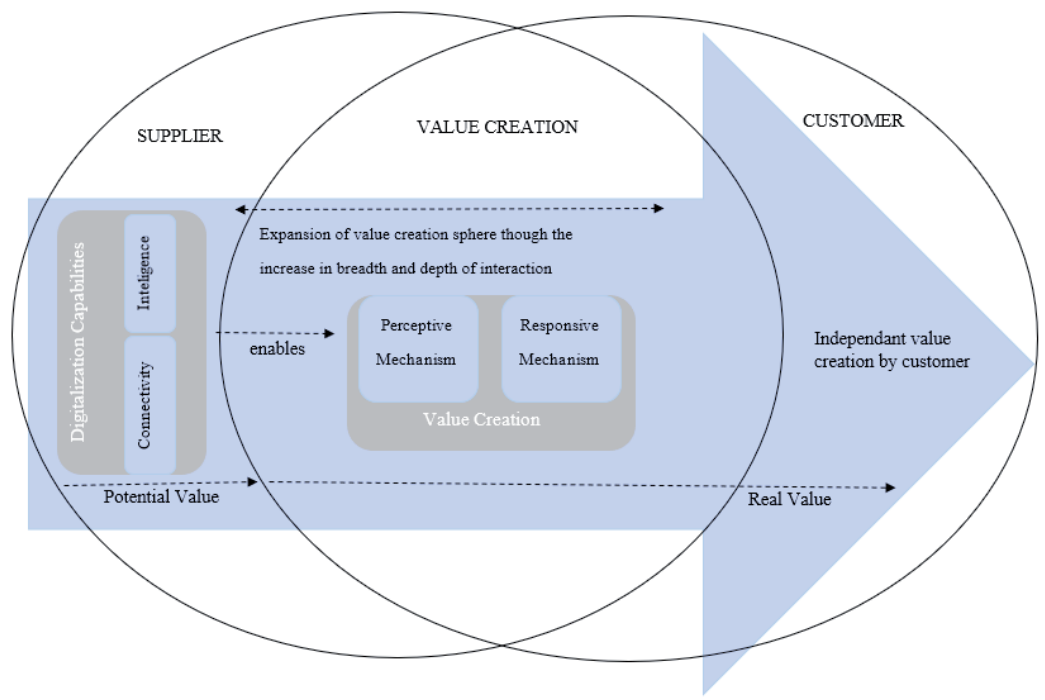

Figure 5 Value creation through digital transformation [5]

- Digitization and automation of processes to optimize use human resources and speeding up operations,

- Real-time planning, supported by an information system, horizontal collaboration on a cloud platform.

In the Figure 5 is a conceptual framework which represents how digital transformation activates interactions between manufacturers and customers. Such cooperation leads to a merged interaction process in which companies form value in a common sphere through increasing depth and width of interaction. In fact, interactions give manufacturing companies the ability to expand the sphere of joint value creation. Value creation is actually the result of interactions between the product supplier and the customer, and digitization increases the interaction between the supplier and the customer and thus enables the value co-creation. Digitization can increase production productivity by leaps and as well significantly reduce costs at the same time.

\section{Conclusions}

Digital transformation becoming a strategy of all businesses that want to be competitive. It is a long term process with all the organizational parties included. The paper clearly points out key elements which must be aligned for smooth digital transformation of industry with main focus on digital transformation technologies. The way of value creation by digitization is identified. At the end of the transformation process a successful industrial company become true digital businesses, with core products enhanced by digital interfaces and innovative services based on the active data use. These digital businesses will work with their customers as well as suppliers in industrial digital ecosystems as is described in the paper. A digitally transformed company is economically healthy, more competitive, has thoroughly cleaned up in operational processes and is a stronger magnet for talents. This research provides implications for companies, who deal with challenges related to digital transformation strategies.

\section{Acknowledgments}

This article was created by implementation of the grant projects VEGA 1/0708/16 "Development of a new research methods for simulation, assessment, evaluation and quantification of advanced methods of production" and APVV-17-0258 Digital engineering elements application in innovation and optimization of production flows

\section{References and Notes}

[1] Bubenik, P, Bubenikova, E, Korbel, P, Nagy, P, (2004). Information Technology for Business Practice. Edis, ŽU in Žilina.

[2] Scheer, A., W. (1994). CIM Computer Integrated Manufacturing Towards the Factory of the Future. SpringerVerlag, Berlin Heidelberg.

[3] Cassidy, A, (2006). A Practical Guide to Information Systems Strategic Planning. Auerbach Publications, Boca Raton.

[4] Kovač, J, Rudy, V, Kovač, Ju, (2017). Methods for the design of production processes. Specifics of designing production 
systems. Edition of professional and scientific literature. SjF TU in Košice.

[5] Laguna, M, Marklund, J, (2013). Business Process Modeling, Simulation and Design. CRC Press, Boca Raton.

[6] Kmec, J, Valenčík, Š, Gombár, M., Karková, M., Vagaská, A. (2016). Logistic Approach of Building and Development of Production Systems. In: Nase More. Vol. 63, No. 3, p. 145-149.

[7] Wiendahl, H, P, Reichardt, J, Nyhuis, P. (2015). Handbook Factory Planning. Springer-Verlag Berlin Heidelberg.

[8] Dulina, L, Edl, M. Fusko, M. Rakyta, M, Sulirova, I, (2018). Digitization in the Technical Service Management System. In: MM Science Journal. No. 1 (2018). p. 2260 - 2266. ISSN 1803-1269

[9] Trebuňa, P., Pekarčíková, M., Kronová, J. (2018) Automation of the casting process by the use of simulation software. Management and Production Engineering Review. Vol. 9, No. 1 82-89, ISSN 2082-1344

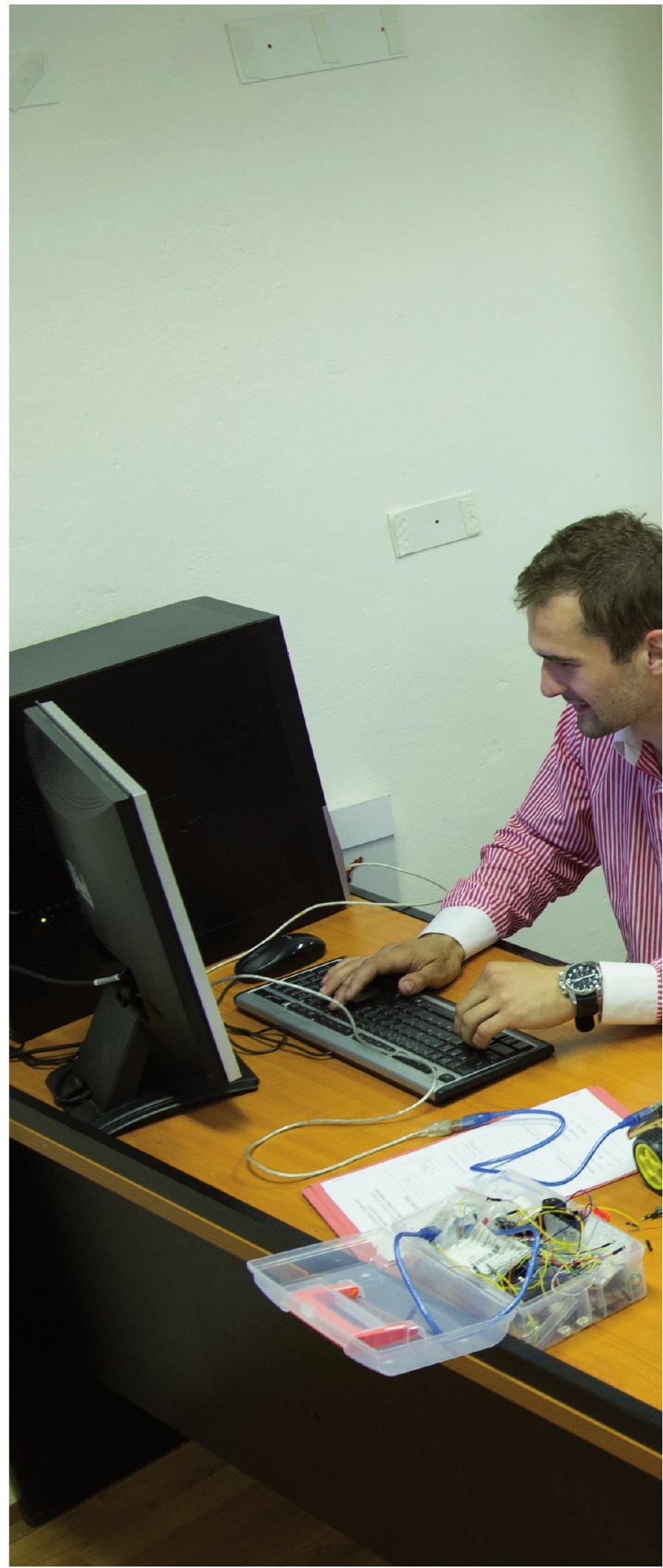

